\title{
COMPARISON OF THE FATTY ACIDS OF LIPIDS OF SUBCELLULAR BRAIN FRACTIONS
}

\author{
Y. Kishimoto, B. W. Agranoff, N. S. Radin and R. M. Burton ${ }^{1}$ \\ Mental Health Research Institute and Department of Biological Chemistry \\ University of Michigan, Ann Arbor, Michigan 48104
}

(Received 10 June 1968)

\begin{abstract}
Rat brain grey and white matter were fractionated to yield myelin, nerve terminal, synaptic vesicle, nerve terminal 'ghost', and microsomal fractions of white and grey matter. Ester-type glycolipids were found in all fractions except myelin, while cerebrosides occurred in significant concentrations only in myelin and white microsomes. Comparison of the fatty acid profile of the ethanolamine- and serine-containing phospholipids showed marked differences between myelin and the particles from grey matter, while the microsomes of white matter were of intermediate composition. Docosahexaenoic acid, a minor acid in myelin, was a major fatty acid in microsomes of grey and white matter. The fatty acid composition of sphingomyelin was distinctly different in the fractions derived from grey and white matter, clustering about stearate and nervonate in the latter, but only about stearate in the grey. Marked differences in the positional distribution of fatty acids were seen within phosphatidyl choline from myelin and nerve terminals. Ribonucleic acid was found in nerve terminal and synaptic vesicle fractions. The sphingosine found in the ganglioside from microsomes of both grey and white matter was similar with respect to distribution of the $\mathrm{C}_{18}$ and $\mathrm{C}_{20}$ homologues.

The possibility is discussed that microsomes furnish characteristic lipids for the synthesis or renewal of specific membranes, and that these lipids are accumulated somewhat before being released.
\end{abstract}

WITH the advent of improved methods for preparing subcellular fractions from brain, many workers have carried out analyses of various lipid classes in the major fractions. We have extended these studies by examining additional brain fractions and by analyzing as well the fatty acids of several lipid classes. It was of particular interest to compare the microsomes of grey and white matter, since the former might be a major source of lipids for neuronal perikarya and synaptic membranes, while the latter may be the source for myelin membranes. Further to elucidate the composition of the synaptic membranes, we analysed three related fractions: the nerve terminals (nerve endings or synaptosomes), the synaptic vesicles, and the nerve terminal 'ghosts', a particulate fraction obtained from the osmotically disrupted nerve terminals. Because of the possible implications of ribonucleic acid in brain function, it seemed of value to examine also the nerve terminal and synaptic vesicle fractions for this material.

\section{MATERIAL AND METHODS}

Preparation of subcellular particles. Sprague-Dawley rats (Holtzman variety) weighing $120-150 \mathrm{~g}$ were killed by decapitation, and the brains were quickly removed, chilled, and homogenized in cold $0.32 \mathrm{M}$-sucrose. The BRODY and BAIN procedure (1952) was used to prepare the crude mitochondrial fraction and the microsomal fraction. All solutions used contained $5 \times 10^{-4} \mathrm{M}$-eserine.

${ }^{1}$ Department of Pharmacology and the Beaumont-May Institute of Neurology, Washington University School of Medicine, St. Louis, Missouri 63110.

Abbreviations used: Solvents are $\mathrm{C}$ (chloroform), $\mathrm{M}$ (methanol), and $\mathrm{W}$ (water). Fatty acids are identified by two numbers, the number of carbon atoms and the number of double bonds (e.g.: 18:1 is octadecenoic acid). 
The mitochondrial fraction was homogenized in $10 \mathrm{vol}$. of water to rupture the terminals (DE Robertis, Rodriguez de lores Arnaiz, Salganicoff, Pellegrino de Iraldi and Zieher, 1963). Fractions were collected by centrifugation at $11,500 \mathrm{~g}$ for $20 \mathrm{~min}\left(\mathrm{M}_{1}\right)$ followed by centrifugation of the resultant supernatant layer at $100,000 \mathrm{~g}$ for $30 \mathrm{~min}\left(\mathbf{M}_{2}\right)$. The $\mathbf{M}_{2}$ pellet was washed three times by resuspension in $0.032 \mathrm{M}$-sucrose and centrifugation $(20 \mathrm{~min}$ at $100,000 \mathrm{~g}$ ) to yield the synaptic vesicle fraction (WHITTAKER, 1959).

The $\mathrm{M}_{1}$ pellet was fractionated by a slight variation of the Whittaker ultracentrifugal procedure, in which the suspended particles in $0.25 \mathrm{M}$-sucrose were layered on $0.8 \mathrm{M}$-sucrose, which had been layered on $1.2 \mathrm{M}$-sucrose. The lower interface material $\left(\mathrm{P}_{2} \mathrm{~B}\right)$ was termed nerve terminal 'ghosts'. The myelin fraction (upper interface material, $\mathrm{P}_{\mathbf{2}} \mathrm{A}$ ) was purified further by the method of LAATSCH, KIES, GORDON and AlVORD (1962).

A total of 109 rats was used to prepare $23 \mathrm{~g}$ of grey matter and $37 \mathrm{~g}$ of white matter, which were used to yield the grey and white microsomal fractions. The myelin, vesicles, and nerve terminal 'ghosts' were obtained from the whole brains of 24 rats ( $43 \mathrm{~g}$ brain). The nerve terminals were processed from the grey matter from 48 rats $(14 \mathrm{~g})$.

All particulate fractions were dialysed against water overnight at $4^{\circ}$, sedimented at high speed, frozen, and stored in dry ice prior to further study. An additional run was made with the cortical matter from 37 rats $(44 \mathrm{~g})$ to yield nerve terminals and vesicles; in this run, the particles were not dialysed before freezing. Samples from trial runs of this procedure were monitored by electron microscopy (BURTON, 1968).

Lipid separations. The particulate fractions were sonicated in a bath with about $10 \mathrm{vol}$. of $\mathbf{C}-\mathbf{M}$ $(1: 1, \mathrm{v} / \mathrm{v})$ and the extracted lipids were separated from the insoluble residue by centrifugation. The residue was washed twice with C-M $(2: 1, \mathrm{v} / \mathrm{v})$ and centrifuging, and the supernatant solutions were pooled. In the case of the particles which had not been dialysed, the sucrose was removed from the lipid extract by dialysis overnight against several portions of water.

The solvent was removed from the extracts by freeze-drying from benzene, following evaporation under vacuum to a small volume in the presence of added benzene. The residue was sonicated in a bath with C-M $(3: 1, v / v)$ and added to a column of silica gel in the same solvent (Unisil 100-200 mesh, Clarkson Chemical Co., Williamsport, Pa.). Further elution with this solvent yielded fraction A, consisting primarily of cholesterol, cerebrosides, sulphatides, and ethanolamine and serine phospholipids. Additional elution, with $C-M(1: 4, v / v)$, yielded fraction $B$, a mixture of ganglioside, lecithin, and sphingomyelin. Qualitative comparisons of the fractions were made by TLC with Silica Gel G, and the lipids were visualized with alkaline bromothymol blue or sulphuric aciddichromate.

The fatty acid esters of both column fractions were converted to methyl esters by alkaline methanolysis (KISHIMOTo, DAVIES and RADIN, 1965). In the case of fraction A, the methyl esters were purified by Florisil chromatography. In the case of fraction B, the lipids were applied to Silica Gel $\mathrm{G}$ plates with the Radin-Pelick Streaker (Applied Science Labs., State College, Pa.) and developed twice with C-M-W-acetone-acetic acid (10:2:1:4:2, by vol) (RouSER, KRITCHEVSKY, GALLI and HeLLER, 1965). The plates were dried $30 \mathrm{~min}$ at $75^{\circ}$ after the first development and air-dried after the second. The sphingomyelin and ganglioside bands were located with bromothymol blue, following which the plates were dried $60 \mathrm{~min}$ at $110^{\circ}$, the bands were transferred to methanolysis tubes (KIsнimoto and RADIN, 1965), and the powder was heated with methanolic $\mathrm{HCl}$ at $100^{\circ}$ overnight. The resultant fatty acid esters were extracted with hexane, the hexane was removed with a stream of nitrogen, and the residue was taken up in carbon disulphide for GLC analysis.

The methyl esters from fraction A were analysed by using a polyester GLC column with Kovar seals (RADIN, 1965), flame ionization detector, and electronic integrator. Tests with standard mixture F from the National Heart Institute (methyl 14:0 to 24:0) showed the absolute errors to be less than a few tenths of 1 per cent for the minor components and no more than 1.1 per cent in the case of the major component $(47.0$ per cent $24: 0)$. The natural ester mixtures showed more variation, with the minor peaks occasionally having absolute errors of 1.0 per cent out of 10 per cent in duplicate runs. The later analyses, with the lipids from the cerebral cortex fractions, were performed with a dual column system, which gave better definition of the peaks with long retention times.

While the hydrogen flame detector is generally believed to yield a lowered response with polyunsaturated acids, a test with recently prepared 22:6 of high purity (Hormel Institute Lipid Preparations Lab.) showed no difference between this and methyl stearate.

The fatty acids from the sphingolipids were analysed with dual Apiezon $L$ columns. 18:Sphingosine and 20: sphingosine were identified by using a modification of methods (SWEELEX and MOSCATELLI, 1959; GAVER and SWEELEY, 1965) in which the unsubstituted aldehydes formed from the sphingosines are separated from interfering methoxy aldehydes by silica gel chromatography. Identification and quantification of the sphingosine types was accomplished by GLC of the purified aldehydes.

Phosphatidyl choline, isolated by TL.C from fraction B lipids, was hydrolysed to lysophosphatidyl choline and fatty acid (from the $\beta$-position) by Crotalus adamantus venom in ether and aqueous $\mathrm{CaCl}_{2}$ 
in tris buffer, $\mathrm{pH} 7.5$ (LANDS and HART, 1964). After $4 \mathrm{hr}$ of vigorous shaking, the incubation mixture was evaporated to a small volume, acidified with citric acid, and freeze-dried with benzene. The residues were treated with $\mathrm{C}-\mathrm{M},(3: 1, \mathrm{v} / \mathrm{v})$ and the extracts chromatographed on silica gel to give the free fatty acids $(\mathrm{C}-\mathrm{M}, 3: 1, \mathrm{v} / \mathrm{v})$ and lysolecithin $(\mathrm{C}-\mathrm{M}, 1: 4, \mathrm{v} / \mathrm{v})$. The former fraction was converted to methyl esters with dimethoxypropane (KISHIMOTo and RADIN, 1963) and the latter by alkaline methanolysis. Since brain phosphatidyl choline preparations contain several per cent of the alkyl and alkenyl ether analogues (RENKONEN, 1966) the methyl esters were purified with a short silica gel column. Another portion of the original phosphatidyl choline was cleaved directly to give the total fatty acid methyl esters. The yield of fatty acids from the degradation process was 82 per cent, of which almost half was from the $\alpha$-position.

Other analyses. The RNA in the particles isolated from cerebral cortex was determined in the residue following C-M extraction (SANTEN and AGRANOFF, 1962). The residue was washed with perchloric acid and treated $15 \mathrm{hr}$ at $4^{\circ}$ with $1.6 \mathrm{~N}$-perchloric acid (Hess and THALHEIMER, 1965). The turbid extract from the nerve terminals was clarified by filtering through Celite. One portion of the RNA extract was diluted with $1.6 \mathrm{~N}$-perchloric acid, and its u.v. absorption determined. Another portion was analysed with the orcinol method (CERIOTII, 1955). Both methods yielded very similar values.

Protein was determined by a modification of the method of LowrY et al. (HESs and Lewin, 1965).

\section{RESULTS}

Qualitative comparisons. TLC of fraction A lipids with C-M-W (24:7:1, by vol.) showed the expected major lipids in all of the brain fractions studied. However, the two cerebroside spots were intense only in the myelin fraction and in the microsomal fraction from white matter. Only trace amounts of $\alpha$-hydroxy cerebroside and no nonhydroxy cerebroside were seen in the other extracts. The distribution of cerebroside sulphate was similar to that of the cerebrosides. The very low concentrations of cerebroside in grey matter subcellular particles are consistent with the reported absence of this lipid in individually isolated neurons (Jornston and RoOTs, 1966).

A particularly noticeable difference among the subcellular fractions was seen in two minor spots found above the cerebrosides following TLC. These two spots were not detectable in myelin but were clearly visible in all of the other fractions. This area on the TLC plate is occupied by a mixture of glycolipids containing esterified fatty acid (NorTon and Brotz, 1963; Kishimoto, WAJDA and Radin, 1968). No effort was made to establish the presence of low concentrations of the glycolipid esters in myelin, such as by a preliminary concentration step.

The lipid patterns of fraction $B$ looked similar for all of the subcellular fractions when studied on TLC with C-M-W $(60: 36: 8$, v/v). The phosphatidyl choline appeared as two partially separated spots, the upper spot apparently containing the more saturated fatty acids. The relative intensities of the two spots matched the GLC data (see Table 3). Such separations have been noted before for other lipids.

The sphingomyelin occurred as pairs of spots in the myelin and white microsome lipids, but the more rapidly migrating spot was less dense in the latter sample. In the particles from grey matter, only the lower spot was visible. These observations are in agreement with the GLC data (Table 2) and the finding by JATZKEWITZ and PILz (1964) that the more rapidly migrating sphingomyelin spot contains the $C_{24}$ cluster of fatty acids.

Fatty acid composition of the phospholipids of fraction $A$. The fatty acid profiles for the nerve terminal, ghost, and synaptic vesicle fractions were quite similar (Table 1). The acids of the microsomes from grey matter showed a similar distribution but stearic acid was higher and 22:6 is a little lower. All four fractions were conspicuous by the very low amounts of $20: 1$, whereas both myelin and microsomes of white matter contained significantly higher quantities. 
TABle 1.-FATTY ACIDS OP ETHANOLAMINE AND SERINE GLYCEROPHOSPHOLIPIDS (expressed as percentage of their total fatty acids)

\begin{tabular}{|c|c|c|c|c|c|c|c|c|}
\hline \multirow[t]{2}{*}{$\begin{array}{c}\text { Fatty } \\
\text { acid }\end{array}$} & \multirow[t]{2}{*}{ Myelin } & \multirow[t]{2}{*}{$\begin{array}{c}\text { White } \\
\text { microsomes }\end{array}$} & \multirow[t]{2}{*}{$\begin{array}{c}\text { Grey } \\
\text { microsomes }\end{array}$} & \multicolumn{2}{|c|}{$\begin{array}{c}\text { Nerve } \\
\text { terminals }\end{array}$} & \multicolumn{2}{|c|}{$\begin{array}{l}\text { Synaptic } \\
\text { vesicles }\end{array}$} & \multirow[t]{2}{*}{$\begin{array}{l}\text { Terminal } \\
\text { 'ghosts' }\end{array}$} \\
\hline & & & & $\mathrm{GM}^{*}$ & $\mathrm{CC} \dagger$ & $\mathrm{WB}_{\ddagger}^{+}$ & $\mathrm{CC} \dagger$ & \\
\hline $16: 0$ & $6 \cdot 3$ & 8.5 & $9 \cdot 9$ & $7 \cdot 6$ & 5 & 9.8 & 5.3 & $7 \cdot 6$ \\
\hline $18: 0$ & 24.9 & $33 \cdot 3$ & 40.5 & $36 \cdot 0$ & $27 \cdot 7$ & $31 \cdot 2$ & $28 \cdot 7$ & $29 \cdot 0$ \\
\hline $18: 1$ & $42 \cdot 4$ & 18.7 & 11.0 & $11 \cdot 6$ & $9 \cdot 2$ & $13 \cdot 4$ & $7 \cdot 8$ & $18 \cdot 5$ \\
\hline $20: 1$ & 8.7 & $5 \cdot 0$ & - & - & - & - & - & - \\
\hline $20: 4$ & $9 \cdot 6$ & $10 \cdot 1$ & 14.0 & $14 \cdot 6$ & 16.4 & $12 \cdot 8$ & $14 \cdot 6$ & 15.9 \\
\hline $22: 4 \omega 6$ & $5 \cdot 7$ & $5 \cdot 1$ & 4.9 & 4.9 & $6 \cdot 2$ & 6.2 & 6.9 & 3.7 \\
\hline $22: 6$ & 2.5 & $19 \cdot 4$ & $19 \cdot 8$ & $25 \cdot 2$ & $31 \cdot 3$ & $23 \cdot 8$ & $32 \cdot 6$ & $24 \cdot 2$ \\
\hline
\end{tabular}

Minor fatty acids, occurring in proportions less than 1 per cent (such as 16:1,18:2, and 22:5w3) are not listed or are shown as dashes. Fraction A lipids were used as the source of the fatty acids. Mass spectrometry has shown the presence of some 18:3 in the 20:1 (SVENNERHOLM, 1968).

* Data from particles isolated from dissected grey matter.

$\dagger$ Particles isolated from cerebral cortex.

† Particles isolated from whole brain.

The profiles for microsomes of both grey and white matter were similar in some respects, particularly in their high concentration of $22: 6$, but differed in the relative proportions of oleate and stearate. Myelin was notable for its high content of oleate and low content of stearate and 22:6. Except for content of 22:6, the microsomes of white matter had a composition intermediate between myelin and microsomes of grey matter.

Fatty acid composition of the sphingomyelins. Grey matter subcellular fractions contained sphingomyelin which had only one major acid, stearate, with small amounts of palmitate and eicosanoate (Table 2). This was seen most clearly in the particles

TABLE 2.-FATTY ACIDS OF SPHINGOMYBLIN (expressed as percentage of total fatty acids)

\begin{tabular}{|c|c|c|c|c|c|c|c|c|}
\hline \multirow[t]{2}{*}{$\begin{array}{l}\text { Fatty } \\
\text { acid }\end{array}$} & \multirow[t]{2}{*}{ Myelin } & \multirow[t]{2}{*}{$\begin{array}{l}\text { White } \\
\text { microsomes }\end{array}$} & \multirow[t]{2}{*}{$\begin{array}{c}\text { Grey } \\
\text { microsomes }\end{array}$} & \multicolumn{2}{|c|}{$\begin{array}{l}\text { Nerve } \\
\text { terminals }\end{array}$} & \multicolumn{2}{|c|}{$\begin{array}{l}\text { Synaptic } \\
\text { vesicles }\end{array}$} & \multirow[t]{2}{*}{$\begin{array}{l}\text { Terminal } \\
\text { 'ghosts' }\end{array}$} \\
\hline & & & & GM* $^{*}$ & $\mathrm{CC} \dagger$ & $\mathrm{WB}_{\ddagger}$ & $\mathrm{CC} \dagger$ & \\
\hline $16: 0$ & $2 \cdot 2$ & $2 \cdot 7$ & $2 \cdot 6$ & 3.5 & 2 & 1.7 & $2 \cdot 1$ & 0.9 \\
\hline $18: 0$ & $31 \cdot 0$ & 62.9 & 89.8 & 92.9 & $94 \cdot 3$ & $88 \cdot 5$ & 95.8 & 97.6 \\
\hline $20: 0$ & 6.6 & 7.0 & 3.0 & $2 \cdot 2$ & $3 \cdot 2$ & 3.6 & $2 \cdot 1$ & $1 \cdot 5$ \\
\hline $22: 0$ & $5 \cdot 4$ & 5.5 & 0.8 & - & - & 1.2 & - & - \\
\hline $22: 1$ & $2 \cdot 2$ & 0.5 & - & - & - & - & - & - \\
\hline $23: 0$ & 0.9 & 0.4 & - & - & - & - & - & - \\
\hline $24: 0$ & 9.8 & 4.8 & $1 \cdot 2$ & $1 \cdot 2$ & - & 0.9 & - & - \\
\hline $24: 1$ & 39.6 & 16.2 & $2 \cdot 5$ & 0.7 & - & 4.0 & - & - \\
\hline $25: 1$ & 0.8 & - & - & - & - & - & - & - \\
\hline
\end{tabular}

* Particles isolated from dissected grey matter.

+ Particles isolated from cerebral cortex.

† Particles isolated from whole brain.

prepared from cortical matter, whereas the other preparations contained small amounts of longer fatty acids (presumably the result of trace contamination with white matter particles). In contrast were the white microsomes and myelin, where the sphingomyelin stearate concentration was markedly lower, and relatively large amounts of nervonate were found.

Fatty acid composition of phosphatidyl choline. Comparison of the total fatty acids (Table 3) revealed that the terminals had much more 16:0 and 22:6, while myelin 
TABLE 3.-Positional Distribution OF FATTY ACIDS IN LECITHIN (expressed as percentage of total acids in each group)

\begin{tabular}{|c|c|c|c|c|c|c|}
\hline \multirow{2}{*}{ Fatty acid } & \multicolumn{3}{|c|}{ Myelin } & \multicolumn{3}{|c|}{ Nerve terminals } \\
\hline & Alpha & Beta & Total & $\overline{\text { Alpha }}$ & Beta & Total \\
\hline $16: 0$ & $32 \cdot 7$ & $16 \cdot 0$ & $22 \cdot 4$ & $53 \cdot 2$ & $45 \cdot 7$ & $48 \cdot 8$ \\
\hline $16: 1$ & $4 \cdot 3$ & $2 \cdot 2$ & $2 \cdot 0$ & $3 \cdot 2$ & 1.4 & $3 \cdot 3$ \\
\hline $18: 0$ & 48.5 & $4 \cdot 5$ & $22 \cdot 6$ & $26 \cdot 1$ & $3 \cdot 8$ & $12 \cdot 5$ \\
\hline $18: 1$ & $14 \cdot 6$ & 62.8 & $42 \cdot 6$ & $17 \cdot 4$ & $32 \cdot 1$ & $24 \cdot 9$ \\
\hline $18: 2$ & - & $2 \cdot 4$ & 1.7 & - & - & - \\
\hline $20: 1$ & - & $5 \cdot 7$ & $4 \cdot 4$ & - & - & - \\
\hline $20: 4$ & - & 6.3 & $4 \cdot 8$ & - & $9 \cdot 7$ & $6 \cdot 3$ \\
\hline $22: 6$ & - & - & - & - & $6 \cdot 5$ & $4 \cdot 0$ \\
\hline
\end{tabular}

had much more 18:0,18:1, 18:2 and 20:1. The fraction A lipids resembled those of fraction $B$ with respect to $22: 6$, which was very low or absent in myelin.

Comparison between the $\alpha$ - and $\beta$-positions showed additional differences. Palmitate was almost equally distributed between the two positions in the nerve terminal fractions, but occupied the $\alpha$-position preferentially in myelin. The $16: 1$, 18:0 and 18:1 distributions were qualitatively similar in both fractions, although the actual values differed somewhat. In the lecithin of both fractions, the polyunsaturated acids occupied the $\beta$-position exclusively. The presence of dipalmitoyl glycerophosphoryl choline in bovine brain was reported by RENKONEN (1966); a large part of this totally saturated phosphatidyl choline is likely present in the nerve endings.

The values for the total fatty acids should be the average of the values for the $\alpha$ and $\beta$-positions, but discrepancies appeared. These were apparently due to losses in handling the small amounts of lipid involved, as well as the presence of some of the ether analogues of phosphatidyl choline. The distribution seen with nerve terminals agrees somewhat with that recently reported for the lecithin of bovine cerebral grey matter (YABUUCHI and O'BRIEN, 1968).

In a separate analysis, the phosphatidyl choline from synaptic vesicle and nerve terminal fractions, obtained from cortical matter, was compared. The distributions of fatty acids from each fraction were similar to each other and to that shown in Table 3 for nerve terminals. Thus in an additional respect there was noted a striking similarity in composition between synaptic vesicle and nerve terminal fractions.

Ribonucleic acid content of nerve terminal and synaptic vesicle fractions. With yeast RNA as standard (Schwarz BioResearch, Orangeburg, N.Y.), the RNA content was $4.4 \mu \mathrm{g} / \mathrm{mg}$ protein in the nerve terminal fraction and $5.0 \mu \mathrm{g} / \mathrm{mg}$ in the vesicles (material from cortex). The absorbancy ratios at $260 / 230 \mathrm{~nm}$ were 2.2 and 2.8 (terminals and vesicles, respectively) while that for yeast RNA was $2 \cdot 6$. The absorbancy ratios at $260 / 280 \mathrm{~nm}$ were, respectively, $1 \cdot 4,1 \cdot 4$ and 1.6. Hess and Thalheimer (1965) reported similar ratios for human frontal cortex and yeast RNA. The perchloric acid extract prepared from myelin gave a slight absorbance at $260 \mathrm{~nm}$, but the spectral absorbancy curve indicated that little or no RNA was present.

Ganglioside. The fatty acid distributions in all fractions studied were very similar to that found in whole rat brain (about 90 per cent 18:0 and the remainder virtually only 16:0 and 20:0). Some ganglioside appeared in myelin, as reported by SuzUKI, PodusLo and Norton (1967). However, myelin prepared by the method of Cumings, Thompson and Goodwin (1968) is said to be free of ganglioside. Perhaps the high 
ionic strength of the caesium chloride used in this method dissociates the glycolipid from the membrane.

The observed concentrations of ganglioside found in each fraction are not reported in view of the subsequent report by SPENCE and WOLFE (1967) that the ganglioside of subcellular brain fractions is extracted only incompletely if the fractions have been dialysed against $\mathrm{Na}^{+}$- and $\mathrm{K}^{+}$-free solutions.

A characteristic of sphingosine in ganglioside is the presence of 20 :sphingosine as well as the more common 18: sphingosine characteristic of cerebroside and sphingomyelin. It seemed possible that the sphingosine in white matter ganglioside was of the $\mathrm{C}_{18}$ type only, while that of grey matter ganglioside was of both types. A comparison with the ganglioside in grey and white microsomes from pig brain disclosed little difference in the ratios of 16:0,16:1, 18:0 and 18:1 aldehydes (derived by periodate degradation as described in the Methods).

\section{DISCUSSION}

Any study in which individual subcellular components are analysed is plagued by the questions of degree of purity and homogeneity and the extent and nature of contaminants. This problem is especially true for brain tissue where many cell types and specialized structures are present. There is heterogeneity among neurons as well as glia. It is obvious from electron microscopic studies that centrifugal methods of separation do not yield homogeneous preparations and not all objects within a field can be identified. However considerable enrichment of specific types of particles can be obtained. Thus myelin can be obtained in a high state of purity, whereas nerve terminals, nerve terminal ghosts and synaptic vesicles are often not homogeneous, being contaminated with membranous material.

The chemical analyses given here support the assignment given our subcellular fractions. (1) Virtually all of the myelin preparation dissolved in C-M. This indicates high purity since the other subcellular particles contain much of their protein in nonproteolipid form (LeEs, 1966). (2) The absence of RNA in our myelin is also a sign of purity. (3) The microsomes isolated from white matter resembled myelin in a number of respects (presence of much cerebroside, certain fatty acids and long-chain sphingomyelin acids) and thus might be suspected of being contaminated with myelin. However, NORTON and AUTILIo (1966) estimated that over one quarter of the cerebroside in bovine white matter occurs outside of the myelin. Moreover, the microsomes of white matter prepared by LAPETINA, SOTO and DE ROBERTIS (1967) contained an even higher concentration of cerebroside than did ours. Cumings et al. (1968), using the very different caesium chloride method for isolating human cortical microsomes, found an appreciable concentration of cerebroside and cerebroside sulphate. Since we found only trace concentrations of these lipids in our preparation of microsomes from grey matter, it may be presumed that these sphingolipids were derived from the white matter present in cerebral cortex. PILZ and MeHL (1966) concluded from an analysis of human myelin and white matter that long-chain sphingomyelin and cerebroside occur in non-myelin particles. The high content of 22:6 in microsomes from both white and grey matter and very low content in myelin, is further evidence of the absence of myelinin the white microsomes. (4) Traces of cerebroside were observed in both preparations of synaptic vesicles, which might therefore be considered to be contaminated with myelin or other white matter material. Nevertheless, the 
sphingomyelin from the vesicles isolated from cortex was virtually free of the $\mathrm{C}_{\mathbf{2 4}}$ cluster of acids, which appears to be a marker for white matter.

Biosynthetic studies in vitro have shown that brain microsomes are probably the major site of synthesis of the fatty acid-containing lipids. It seems likely that these lipids are incorporated into membranes characteristic of the cell type; that is, white matter microsomes make myelin lipids and grey matter microsomes make nerve terminal lipids. This report, which shows that microsomes of white matter resemble both myelin and grey microsomes in composition, is consistent with the concept that the microsomes contain two types of lipids: the first is characteristic of the membranesynthesizing organelle, being similar in microsomes from both grey and white matter; the second is characteristic of recently synthesized 'protomembrane' lipids, which have yet to be detached from the microsomes and transported to the appropriate site.

Microsomes appear to form fatty acids primarily by elongation of lipid-bound intermediate fatty acids (KISHIMoto and RADIN, 1966; GuchHAIT, Putz and PoRTER, 1966), using malonyl-CoA as elongating agent. It appears from the fatty acid analyses of sphingomyelin that the elongating enzyme of grey matter particles cannot readily go beyond 20:0, whereas the microsomal elongating enzyme of white matter can go to $24: 0$ and $24: 1$. This difference does not exist for the elongating systems acting on the polyunsaturated acids, for 22:6 is found in microsomes of white and grey matter. It is possible that two different elongation systems exist, one for polyunsaturated acids and another for the other acids, and that two forms of the latter system occur in white and grey microsomes. An alternative explanation is that two sphingomyelin synthesizing enzymes exist, one that utilizes only the $\mathrm{C}_{18}$ cluster of acids, the other (in microsomes of white matter only) utilizing only the $\mathrm{C}_{24}$ cluster.

Our data for grey matter particles and myelin can be compared with previously published data. The observation that human myelin has a low concentration of $22: 6$ and high concentration of 18:1 was reported by O'BRIEN and SAMPSON (1965). Their values for the proportions of fatty acids in lecithin of myelin are approximately in agreement with ours, except that they found no 20:1 and much less 20:4. These and other authors (Foote, Allen and Agranoff, 1965; Svennerholm, 1968) also noted differences between white and grey matter that are similar to our findings for the subcellular particles of white and grey matter. The existence of two clusters of fatty acids in sphingomyelin was noted by STÄLLBERG-STENHAGEN and SVENNERHOLM (1965), who concluded that the longer acids were characteristic of myelin.

Palmitic acid, the primary product of fatty acid synthetase, occurs largely in lecithin. This is also seen in the distribution study of O'BRIEN and SAMPSON (1965) with human brain. Judging by turnover studies with labelled acetate (HAJRA and RADIN, 1963), many of the molecules of the longer fatty acids are formed from palmitate that is not newly formed, but that is bound initially into complex form. It is possible, in view of the above findings, that microsomal lecithin is the major source of the longer fatty acids. Lecithin is known to be a fatty acid donor for the transferase which forms the cholesterol esters seen in plasma (GLOMSET, 1968).

The absence of RNA in myelin noted here is in agreement with the work of AUTILIO, NORTON and TERRY (1964), while the presence of RNA in nerve terminals is corroborated by AUSTIN and MORGAN (1967), who reported somewhat higher 
concentrations, $12 \mu \mathrm{g} / \mathrm{mg}$ protein. MORGAN and AUSTIN (1968) recently gave evidence for the synthesis of proteins in nerve terminals.

Acknowledgements-The authors are greatly indebted to Mrs. CAROLYN SErDL, Mr. W. P. KoLB, and Mrs. Sipra BASU for their assistance in the chemical analyses, and to Mrs. JANE GibBons and Mrs. ULRIKE TAYLOR for their assistance in preparing the subcellular particles. Dr. SARAH LuSE kindly made electron microscopic examinations of the particles during the development of the isolation procedures, and Dr. J. LiNDSLEY FOOTE carried out helpful studies in the development of the lipid methods. Highly purified polyunsaturated fatty acid standards were the generous gift of Dr. O.S. PRIVETT and J. NADENICEK. This research has been supported by grants from the National Institute of Neurological Diseases and Blindness, NB 03101, NB 03192, and NB 01575, U.S. Public Health Service.

This work was reported in preliminary form at the April 1967 meeting of the Federation of American Societies for Experimental Biology (RAdin, KisHimoto, AGraNorf and BuRTON, 1967).

\section{REFERENCES}

Austin L. and Morgan I. G. (1967) J. Neurochem. 14, 377.

Autilio L. A., Norton W. T. and Terry R. D. (1964) J. Neurochem. 11, 17.

Brody T. M. and BaIN J. (1952) J. biol. Chem. 195, 685.

Burton R. M. (1968) In Drugs and Poisons as Etiological Agents in Mental Retardation (Edited by MCKhanN G. and YAFre S. J.). U.S. Government Printing Office, Washington, D.C.

Ceriotti G. (1955) J. biol. Chem. 214, 59.

Cumings J. N., Thompson E. J. and Goodwin H. (1968) J. Neurochem. 15, 243.

De Robertis E., Rodriguez de Lores arnaiz G., Salganicoff L., Pellegrino de Iraldi A. and ZIEHER L. M. (1963) J. Neurochem. 10, 225.

Foote J. L., Allen R. J. and Agranofy B. W. (1965) J. Lipid Res. 6, 518.

Gaver R. C. and Sweeley C. C. (1965) J. Amer. Oil Chem. Soc. 42, 294.

Glomser J. (1968) J. Lipid Res. 9, 155.

Guchiatt R. B., Putz G. R. and Porter J. W. (1966) Arch. Biochem. Biophys. 117, 541.

HajRa A. K. and Radin N. S. (1963) J. Lipid Res. 4, 270.

Hess H. H. and Lewin E. (1965) $J$. Neurochem. 12, 205.

Hess H. H. and ThalHEImer C. (1965) J. Neurochem. 12, 193.

JATZKewitz H. and PILZ H. (1964) Naturwissenshaften 51, 61.

Johnston P. V. and Roots B. I. (1966) Biochem. J. 98, 157.

Kishimoto Y., Davies W. E. and RadiN N. S. (1965) J. Lipid Res. 6, 525.

KIstrmoto Y. and RadiN N. S. (1963) J. Lipid Res. 4, 130.

Kishimoro Y. and RADIN N. S. (1965) J. Lipid Res. 6, 435.

Kishimoto Y. and RADIN N. S. (1966) Lipids 1, 47.

Kishimoto Y., WAJDA M. and RAdIN N.S. (1968) J. Lipid Res. 9, 27.

LAATSCH H., Kies N. W., Gordon S. and Alvord E. C. (1962) J. exp. Med. 115, 777.

LANDS W. E. M. and HART P. (1964) J. Lipid Res. 5, 81.

Lapetina E. G., Soto E. F. and De Robertis (1967) Biochim. biophys. Acta 135, 33.

LEES M. B. (1966) J. Neurochem. 13, 1407.

MoRgAN I. G. and AuSTIN L. (1968) J. Neurochem. 15, 41.

Norton W. T. and Autriuio L. A. (1966) J. Neurochern. 13, 213.

Norton W. T. and Brotz M. (1963) Biochem. Biophys. Res. Commun. 12, 198.

O'Brien J. S. and SAMPson E. L. (1965) J. Lipid Res. 6, 545.

PILZ H. and MeHL E. (1966) Hoppe-Seylers physiol. Chem. 346, 306.

Radin N. S. (1965) J. Chromatog. 20, 392.

Radin N. S., Kishimoto Y., Agranofy B. W. and Burton R. M. (1967) Fed. Proc. 26, 676.

RENKONEN O. (1966) Biochim. biophys. Acta 125, 288.

Rouser G., Kritchevsky G., Galli C. and Heller D. (1965) J. Amer. Oil Chem. Soc, 42, 215.

SANTEN R. J. and AGRANOFF B. W. (1962) Biochim. biophys. Acta 72, 251.

SPENCE M. W. and WOLFE L. S. (1967) J. Neurochem. 14, 585.

StäLlberg-Stenhagen S. and SvenNerholm L. (1965) J. Lipid Res. 6, 146.

Suzuki K., Poduslo S. E. and Norton W. T. (1967) Biochim. biophys. Acta 144, 375.

SVRNNERHOLM L. (1968) J. Lipid Res. 9, 570.

SWeeley C. C. and Moscatelli E. A. (1959) J. Lipid Res. 1, 40.

WHITTAKER V. P. (1959) Biochem. J. 72, 694.

YABUUCHI H. and O'Brien J. S. (1968) J. Lipid Res. 9, 65. 